\title{
Rancang Bangun ECG Simulator Menggunakan Digital to Analog Converter R-2R
}

\author{
Mulyatno Saimi \\ Program Studi Sarjana Terapan Teknik Elektromedik, Fakultas Kesehatan, Universitas Mohammad \\ Husni Thamrin. \\ Correspondence Author : pa.mulyatno@gmail.com \\ DOI: https://doi.org/10.37012/jtik.v7i1.531
}

\begin{abstract}
Abstrak
Pengujian atau mengkalibrasi alat Electro CardioGraph membutuhkan alat ECG simulator / phantom. Saat melakukan penelitian terdahulu, peneliti sangat tergantung dengan komponen DAC impor. Penelitian ini merupakan lanjutan penelitian terdahulu dengan menggunakan komponen yang banyak terdapat di Indonesia. Ini adalah penelitian eksperimen, menggunakan metode System Development Life Cycle, dengan tahapan merancang, membangun dan menguji, Spesifikasi ECG simulator yang akan di bangun, mampu menghasilkan sinyal ECG Normal, Sinusiodal dan Square, dengan beat rate 30, 60, 80, 120, 240 dan 300 BPM, dan amplitude pada pengukuran Lead II 0,5 Volt, 1 Volt, 1,5 volt dan 2 Volt. Memiliki output 10 terminal standard ECG. Kontrol dan pengolahan sinyal menggunakan Arduino pro mini, data digitalisasi ECG diperoleh dengan memperbesar cetakan sinyal ECG pada kertas kotak-kotak/grid, data sinusoidal dibuat menggunakan fungsi sin microsoft excel, sedang data digitalisasi square memberikan nilai output high dan low. Kemudian data digitalisasi diumpan ke serial to pararel IC 74595 dan DAC R2R untuk menghasilkan sinyal analog dan terakhir ke pembagi tegangan untuk terminal. Nilai resistor-resistor pembagi tegangan didapat perhitungan dan percobaan dari penelitian kami sebelumnya. Hasil pengujian menggunakan software simulasi di layar komputer, masih terlihat gradiasi konversi yang belum sempurna, tetapi cetakan pada alat ECG tidak terlihat. Pengukuran BPM sangat akurat, $100 \%$ sama antara nilai pemilihan Simulator dengan yang tercetak pada kertas ECG. Pengukuran amplitudo pada Lead II, mendekati nilai yang dipilih simulator.
\end{abstract}

\section{Kata kunci : ECG Simulator, ECG Phantom.}

\begin{abstract}
Testing or calibrating the Electro Cardio Graph tool requires an ECG simulator / phantom tool. When conducting previous research, researchers were very dependent on imported DAC components. This study is a continuation of previous research using components that are widely available in Indonesia.This is an experimental research, using the System Development Life Cycle method, with the stages of designing, building and testing, the ECG simulator specifications to be built are capable of producing Normal, Sinusiodal and Square ECG signals, with beat rates of 30,60, 80, 120, 240 and 300 BPM, and amplitude on Lead II measurements of 0.5 volts, 1 volts, 1.5 volts and 2 volts. Has an output of 10 standard ECG terminals. Control and signal processing uses Arduino pro mini, ECG digitization data is obtained by enlarging the ECG signal print on grid / grid paper, sinusoidal data is made using the sin() function of microsoft excel, while square digitization data provides high and low output values. Then the digitization data is fed to the serial to parallel IC 74595 and DAC R2R to produce an analog signal and finally to the voltage divider for the terminal. The values of the voltage divider resistors are calculated and tested from our previous research. The test results using simulation software on a computer screen show that the conversion gradient is not yet perfect, but the print on the ECG tool is not visible. The BPM measurement is very accurate, 100\% the same between the Simulator selection value and the one printed on the ECG paper. The amplitude measurement on Lead II is close to the value selected by the simulator.
\end{abstract}

Keyword : ECG Simulator, ECG Panthom 


\section{Pendahuluan}

Perundang-undangan dan peraturan pemerintah pun mewajibkan secara berkala pengujian dan kalibrasi peralatan medis (UU No.44/2009 pasal 16 ayat $7^{[2]}$ ), untuk mengkalibrasi pesawat ECG dibutuhkan ECG simulator, tetapi banyak rumah sakit di daerah yang belum memiliki ECG simulator, umumnya beralasan masalah pengadaan dan tidak dianggap prioritasnya dan harga yang relative lebih mahal dibanding untuk kebutuhan lainnya.

Penelitian terdahulu yang penulis lakukan dalam tim ${ }^{[1]}$, sangat tergantung dengan komponen DAC yang impor. Karena itu peneliti melakukan penelitian lanjutan ini menggunakan komponen yang umum banyak di Indonesia.

Rangkaian R2R digital to analog converter sederhana terbuat dari susunan Resistor seperti anak tangga, digunakan untuk pembelajaran DAC dan beberapa implementasi ${ }^{[3],[4],[5]}$ dan ${ }^{[6]}$.



Gambar 1. Rangkaian DAC R2R

Alat ECG berfungsi mengukur dan merekam aktifitas listrik pada jantung. Terdapat standard pengukuruan dari beberapa posisi sebagai berikut ${ }^{[7]}$ :

A. Sandapan Standar Bipolar (Willem Einthoven's original Lead)

Sandapan standar bipolar mencatat beda potensial di dua titik, dimana jantung dan ekstremitas terletak dalam satu bidang frontal.

1. $\mathrm{L} \mathrm{I}=$ mencatat perbedaan potensial antara lengan kiri dan lengan kanan (LA - RA).

2. $\mathrm{L}$ II $=$ mencatat perbedaan potensial antara kaki kiri dan lengan kanan(LL $-\mathrm{RA})$.

3. $\mathrm{L}$ III = mencatat perbedaan potensial antara kaki kiri dan lengan kiri $(\mathrm{LL}-\mathrm{LA})$. 
B.Unipolar Augmented Extremity (Goldberger's Lead):

1. Lead aVR: RA (+) ke [LA \& LL] (-) (Rightward)

2. Lead aVL: LA (+) ke [RA \& LL] (-) (Leftward)

3. Lead aVF: LL (+) ke [RA \& LA] (-) (Inferior)

C. precordial leads (Chest/horizontal plane):

Leads V1, V2, V3: (Posterior Anterior)

Leads V4, V5, V6:(Right Left, or lateral)

Arduino adalah sebuah platform fisik computing open-source berbasis simple I/O Board termasuk bahasa pemogramannya dan Software pengembangan (IDE). ${ }^{[8]}$

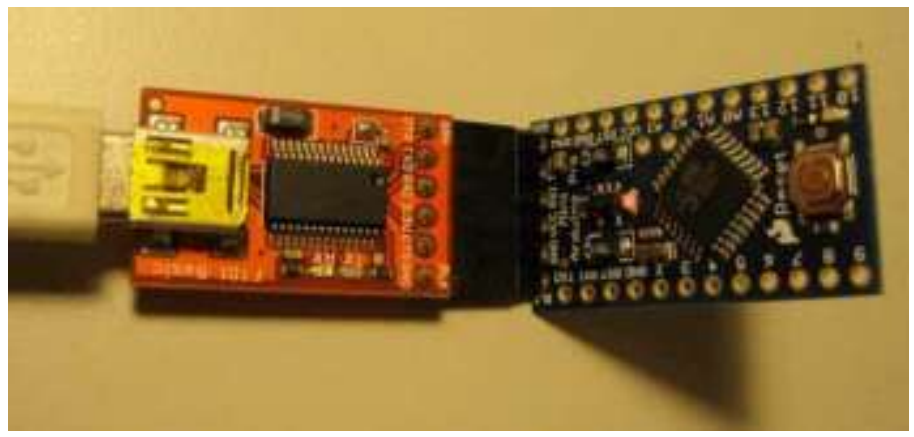

Gambar 2. Arduino Pro Mini ${ }^{[9]}$.

IC 74HC595 komponen elektromnik yang berfungsi untuk konversi dari data digital serial menjadi pararel 8 bit $^{[10]}$.

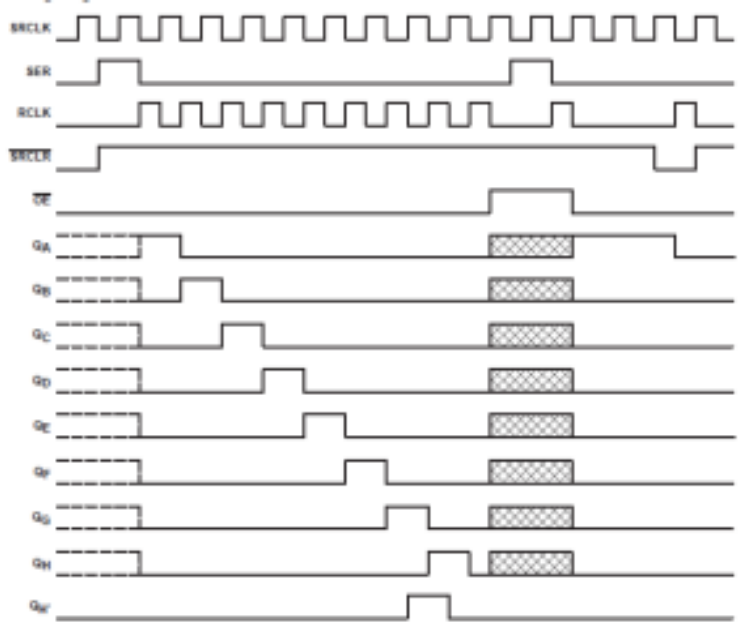

Gambar 3. Timing diagram 74HC595 ${ }^{[10]}$. 
Liquid Crystal Display (LCD) merupakan suatu jenis media tampilan yang menggunakan kristal cair sebagai penampil utama. LCD yang akan digunakan dalam rancang bangun ini adalah LCD 16x2. LCD tersebut mempunyai ukuran lebar display 2 baris dan 16 kolom atau biasa disebut dengan LCD Karakter 16x2 $2^{[11]}$. Awalnya LCD ini menggunakan driver HD44780U ${ }^{[12]}$, tetapi saat ini sudah banyak Clone / kompatibelnya.
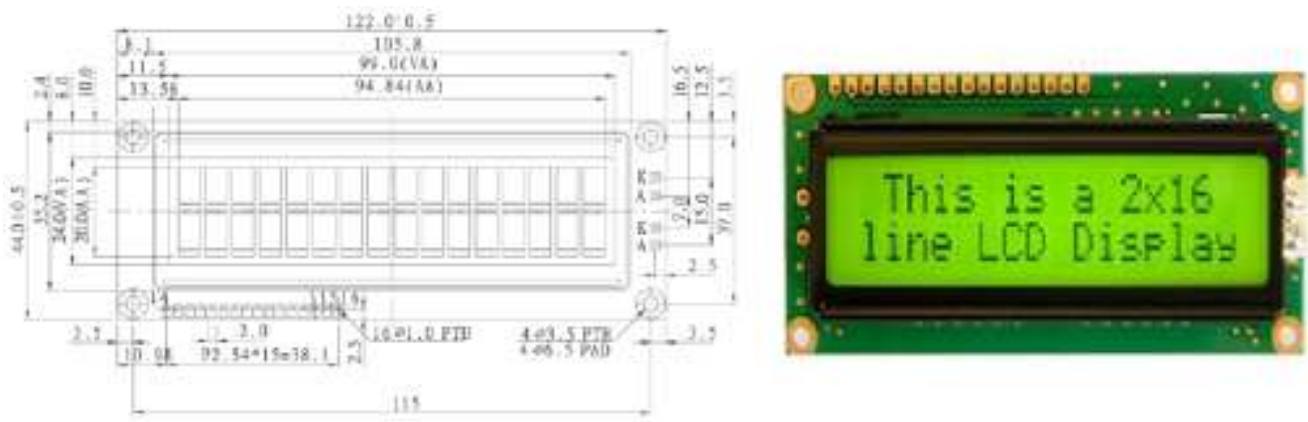

Gambar 4. LCD Karakter 16x2 ${ }^{[11]}$

Tujuan penelitian ini merancang, membangun dan menguji ECG simulator menggunakan Digital to Analog Converter R2R.

\section{Metode PelaksanaAn}

Penelitian ini menggunaka metode system development life cycle (SDLC), dengan tahapan sebagai berikut :

1. Analisa kebutuhan pengguna.

Obeservasi yang penulis lakukan pada penelitian sebelumnya, beberapa rumah sakit umumnya sudah memiliki alat ECG, tetapi masih banyak yang belum memiliki ECG simulator untuk kebutuhan pemeliharaan dan kalibrasi. Berdasarakan observasi tersebut kami membuat spesifikasinya. 
Tabel 1. Spesifikasi awal yang kami tentukan

\begin{tabular}{l|l} 
Bentuk Gelombang & ECG, Square dan Sinusodial \\
\hline Frequensi cardiac & $30 \mathrm{BPM}$ to $300 \mathrm{BPM}$, deviasi $0 \%$ to $20 \%$ \\
Amplitudo & $0.5 \mathrm{mV}, 1 \mathrm{mV}, 2 \mathrm{mV}$, deviasi $0 \%$ to $20 \%$ \\
Leads & $12(\mathrm{Pin})$ \\
Energy source & Standard 9V battery or 9VDC wall adapter \\
Display & LCD 2 X 16 Character
\end{tabular}

2. Mendesain Rangkaian dan flowchart.

a. Mendesain Blok skema

Penghasil pulsa terdiri dari Microcontrller / Arduino mini pro diumpan ke serial to pararel,di konversi menjadi sinyal analog oleh DAC R24, difilter ripple yang terjadi dan dilakukan pemilihan amplitude dan terakhir pembagi tegangan untuk menghasilkan tenganan dimasing-masing 10 terminal lead



Gambar 5. Desain Blok skema

b. Mendesain Digram Alur Software

Desain diagram alur / flowchart software pada arduino pro mini, sebagai berikut : 


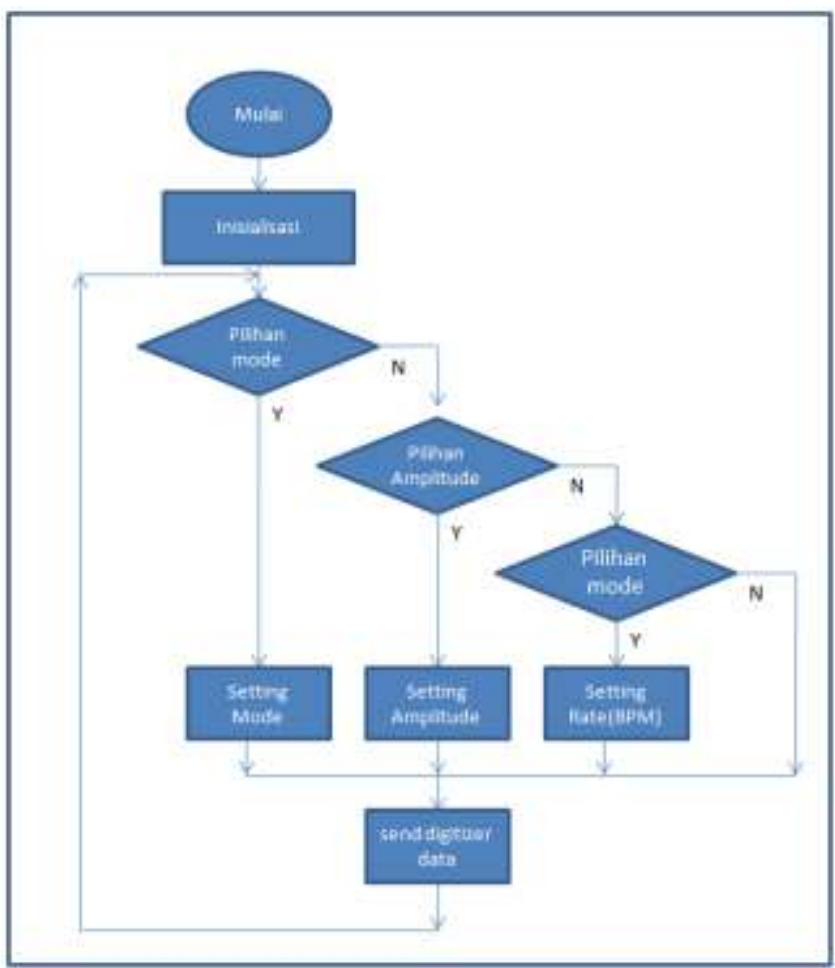

Gambar 6. Desain Blok skema

3. Konstruksi / pembuatan

a) Rangkaian pemilihan dan display

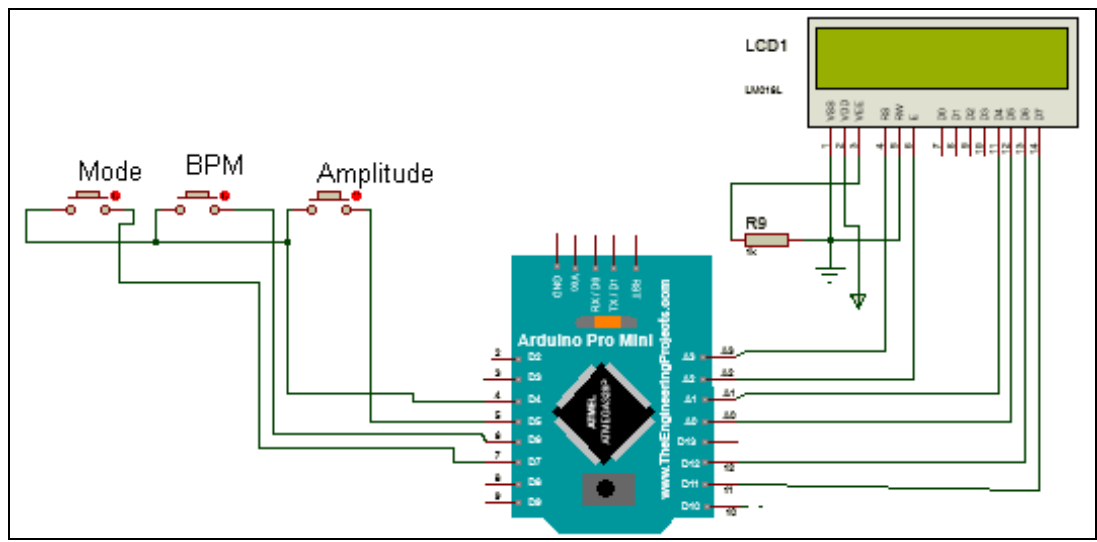

Gambar 7. Rangkaian Pemilihan dan Display 
b) Rangkaian Serial to Pararel, DAC R2R dan Rangkaian filter

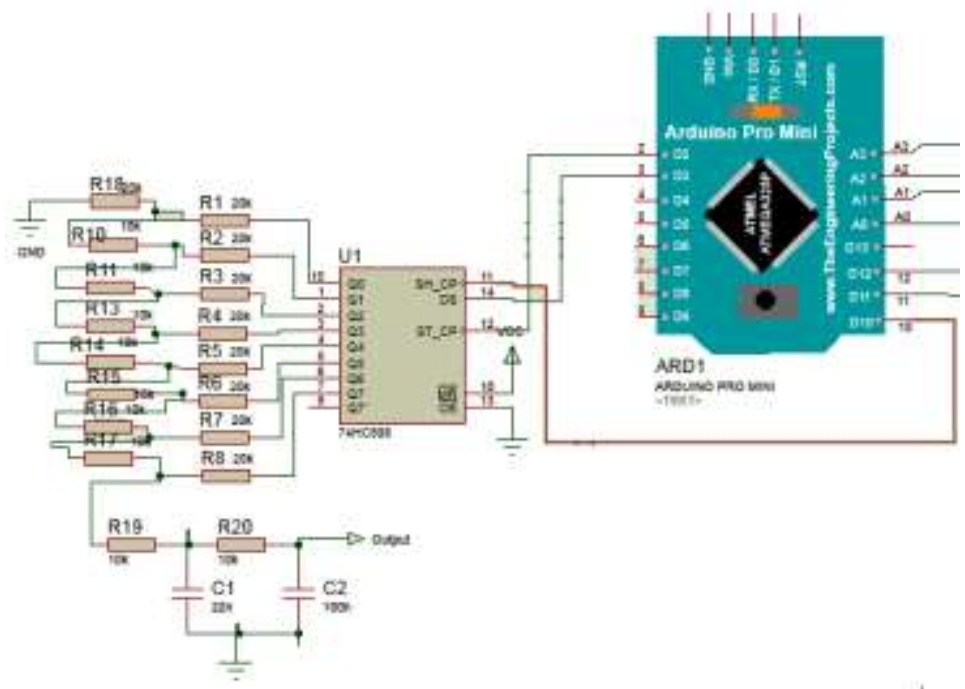

Gambar 8. Rangkaian Serial to Pararel, DAC R2R dan Rangkaian filter

c) Rangkaian pemilihaan amplitude

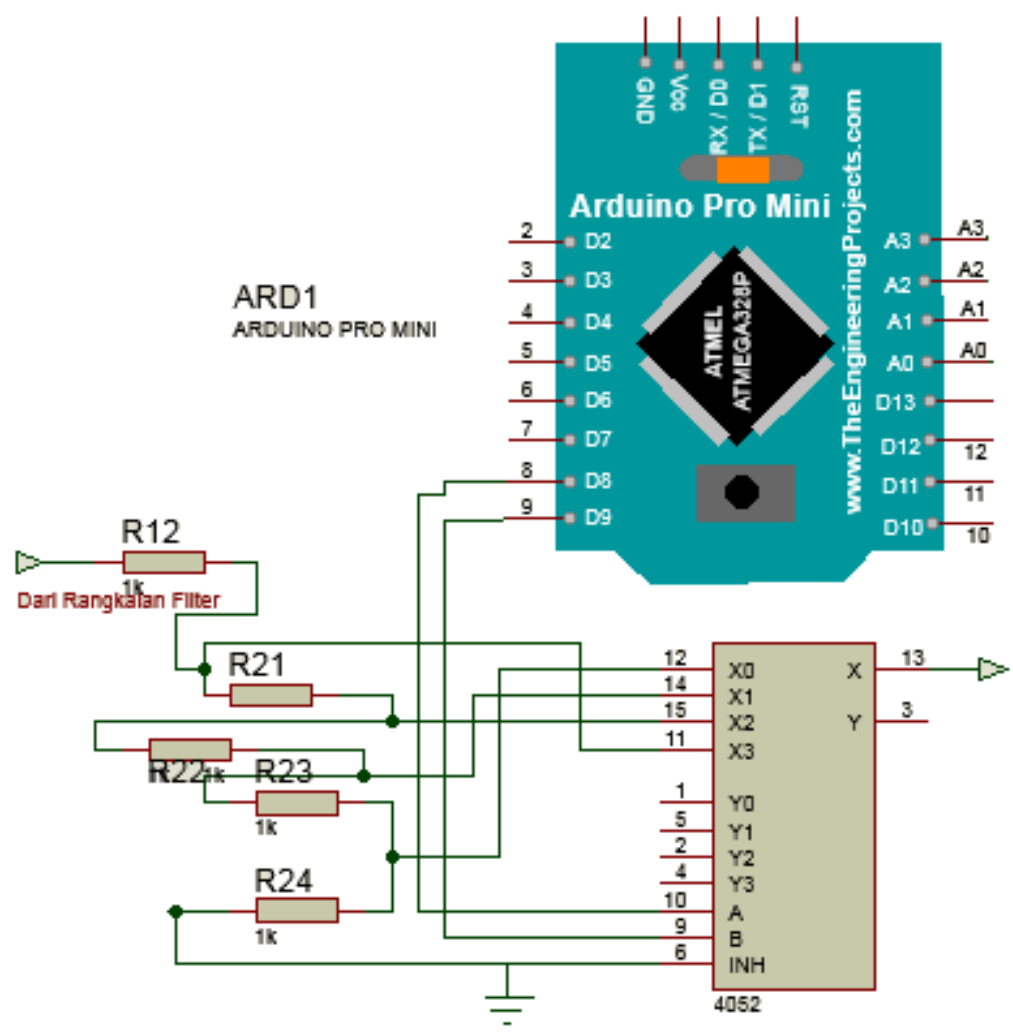

Gambar 9. Rangkaian Pemilihan Amplitude 
d) Rangkaian pembagi tegangan



Gambar 9. Rangkaian pembagi tegangan

4. Pengujian

Pengujian dilakukan di kampus Universitas MH Thamrin,tahapannya mulai dari menggunakan software simulator, kerja per-rangkaian hingga uji coba sistem keseluruhan.

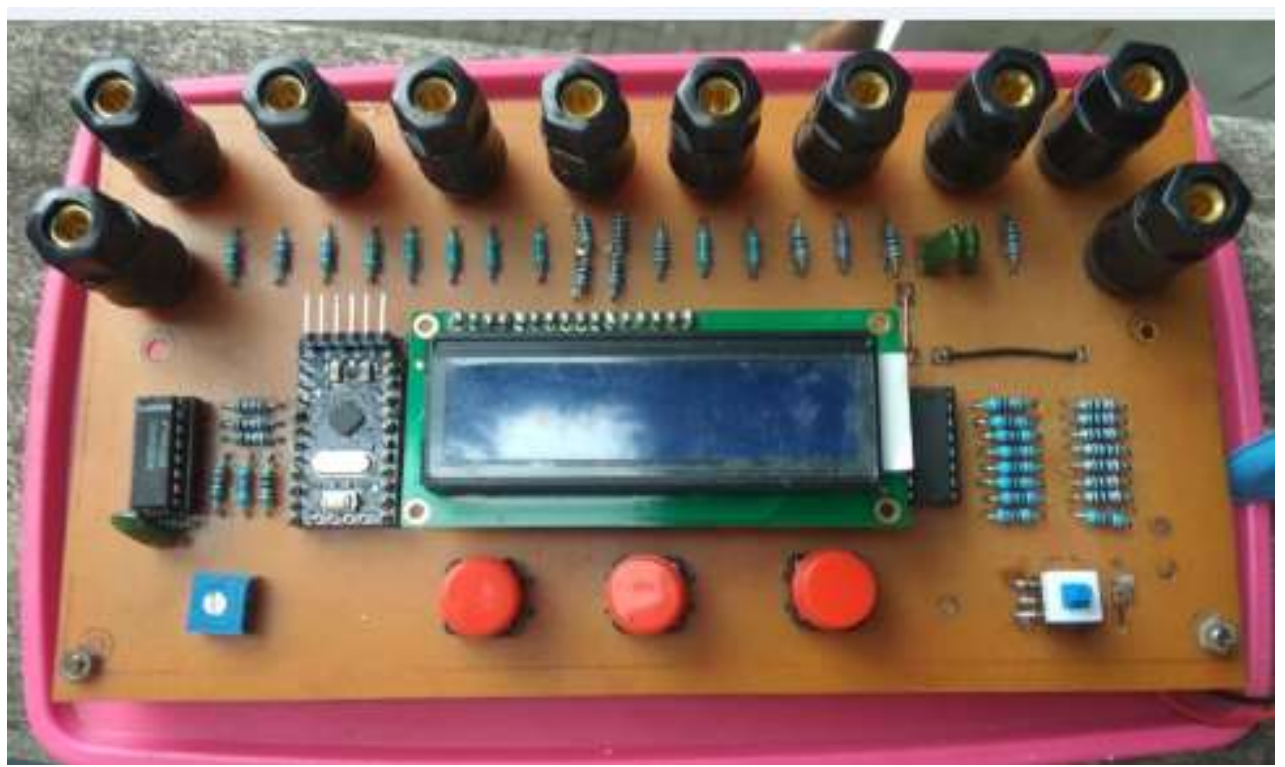

Gambar 10. Hasil akhir alat ECG simulator yang diujikan 
Saat pengujian sering kali, uji coba berulang / iterasi kemudian perbaikan sistem atau kalibrasi agar sesuai dengan spesifikasi yang ditentukan. Pada akhir uji coba akhir ke alat ECG, merk KENZ ECG 110.

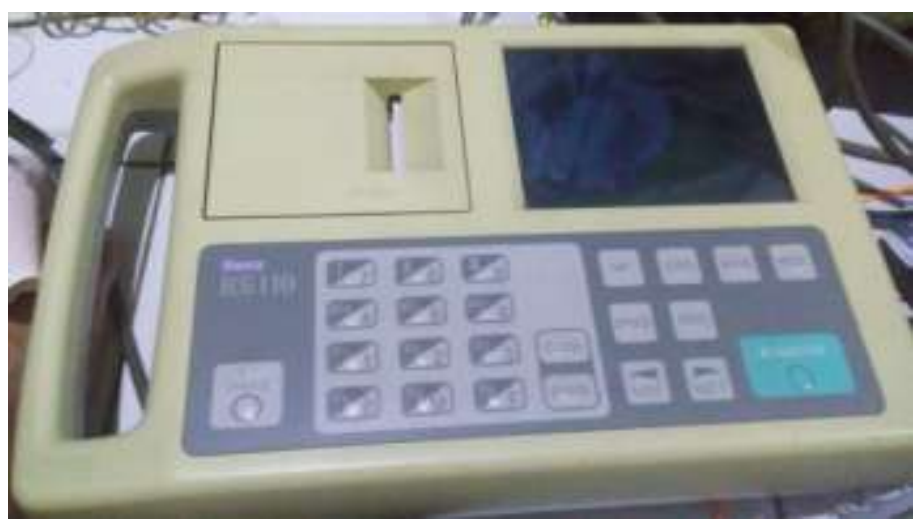

Gambar 11. Pesawat ECG, merk KENZ ECG 110

Setting amplitude memilih besaran amplitude $(0.5 \mathrm{mV}, 1 \mathrm{mV}, 1.5 \mathrm{mV}$ atau $2 \mathrm{mV})$ dengan mengerakan pin A dan B pada IC 4052, nilai teganggnya berdasarkan perhitungan/persamaan voltage divider, kemudian disesuaikan/kalibrasi dengan pengaturan $\mathrm{R}$ variable. Setting Mode memilih sinyal ECG, sinus atau Square dengan memilih prosedur nilai-nilainya yang akan dibangkitkan. Setting BPM memilih delay antara satu nilai dengan nilai lainnya dari sinyal yang akan dibangkitkan, delay ini berdasarkan trial and error,menggunakan software simulasi.

\section{Hasil dan Pembahasan}

Pengujian menggunakan software simulasi,walaupun sudah melalui filter masih terlihat gradasi. 




Gambar 12. Pengujian menggunakan oscilloscope software.

Hasil pengujian pada gelombang atau mode square dan sinusoida pada Lead II,Setting tinggi amplitude 1 milivolt, pada hasil cetakan ECG terbaca, hampir sama dengan yang disetting dapat dikatakan akurat. Pesawat ECG-nya memiliki fitur menditeksi Heart Rate / BMP, karena bukan gelombang ECG maka HR/BPM tidak terditeksi.

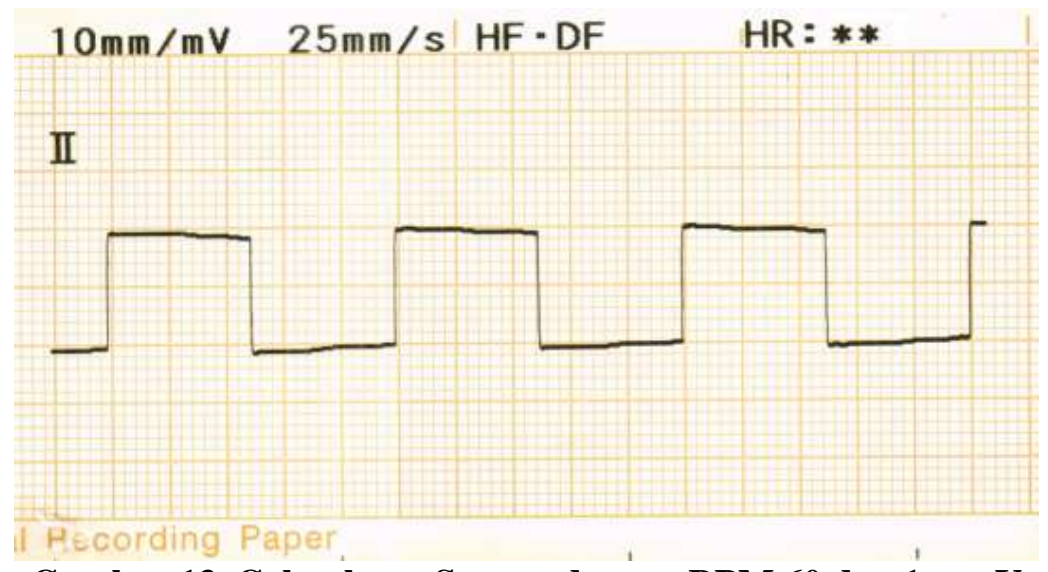

Gambar 13. Gelombang Square dengan BPM 60 dan 1 mmV 


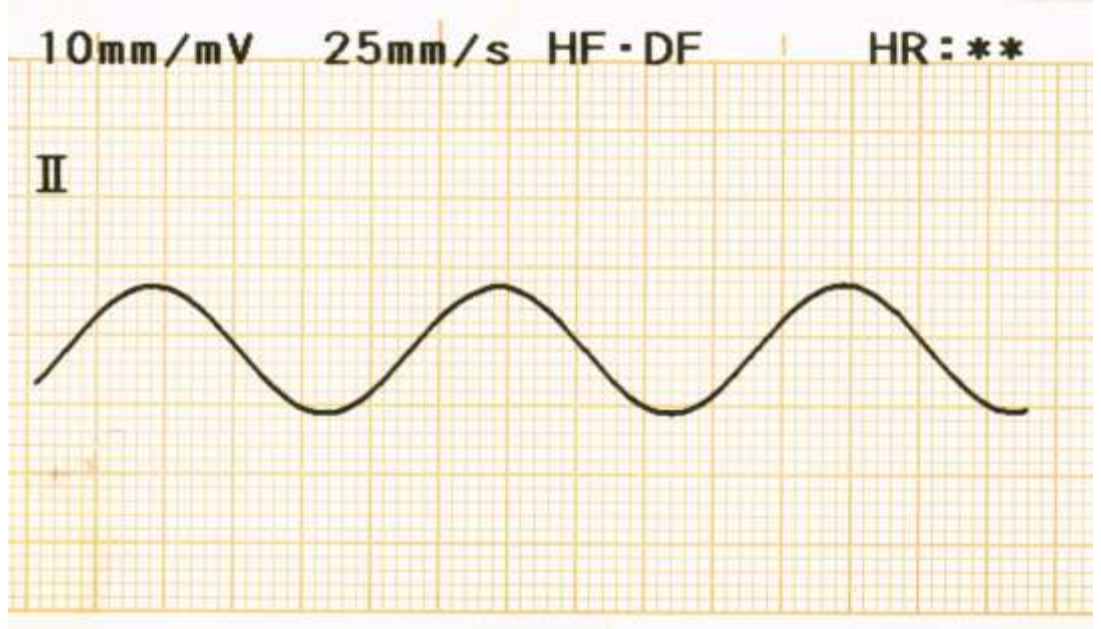

Gambar 14. Gelombang Sinusodal dengan BPM 60 dan 1 mmV

Hasil pengujian pada gelombang /mode ECG normal pada Lead II,Setting tinggi amplitude 1 milivolt dan BPM=60, pada hasil cetakan ECG terbaca, juga hampir sama dengan yang disetting dapat dikatakan akurat. Heart Rate / BMP pada pesawat ECG juga sesuai dengan yang disetting pada ECG simulator yaitu $\mathrm{HR}=60$.

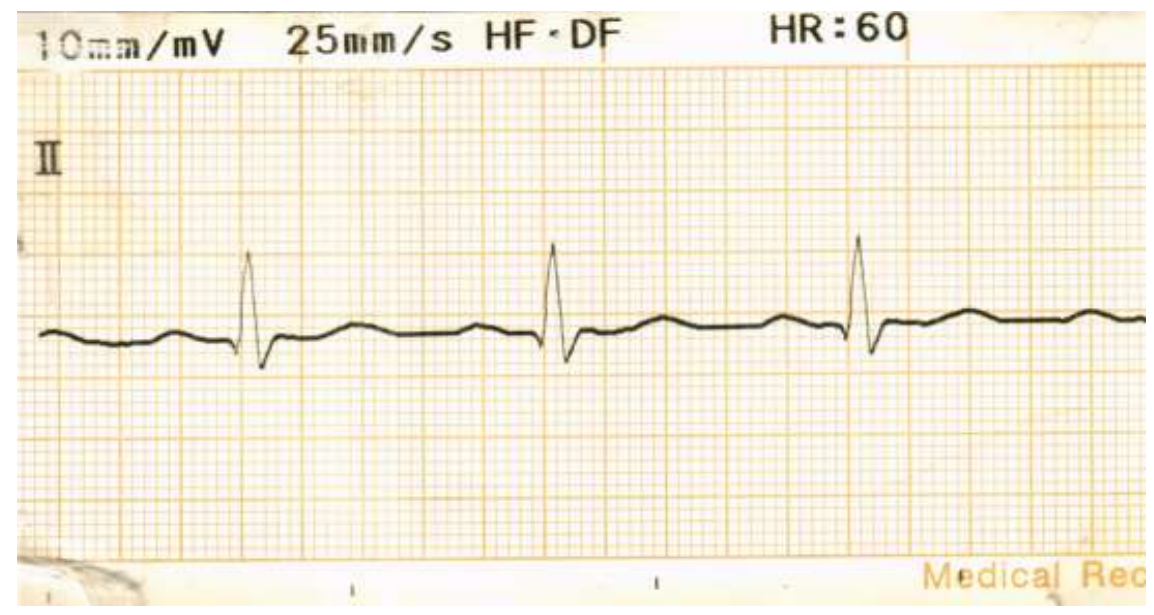

Gambar 16. Gelombang ECG dengan BPM 60 dan 1 mmV, pengukuran Lead II 


\section{SIMPULAN}

Dari hasil penelitian "Rancang Bangun ECG Simulator Menggunakan Digital To Analog

Converter R-2R " ini, disimpulkan sebagai berikut :

1. Pengujian menggunakan software proteus masih terlihat gradasinya

2. Pengujian dengan pesawat ECG gradasinya tidak terlalu nampak.

3. DAC R2R yang penulis gunakan 8 bit, Jika disbanding dengan penelitian sebelumnya menggunakan ADC 12 bit sangat jauh perbedaan gradasi atau resolusi pada software simulasi.

4. Alat ECG simulator berfungsi dengan baik, menghasilkan keluaran sesuai dengan spesifikasi yang telah ditentukan.

\section{DAFTAR PUSTAKA}

[1] R. Candra Jepi Destriawan ,Mulyatno dan Hendra Mawarzi, Rancang Bangun ECG Simulator Berbiaya Rendah, 2016

[2] Undang-undang Nomor 44 tahun 2009 tentang Rumah Sakit, Sekertariat Negara 2009.

[3] K. Gopalan, Introduction to Digital Microelectronic Circuits, Tata McGraw-Hill, New Delhi, 1998.

[4] Arif Widodo,Farid Baskoro, Rosmita Dwijayanti, Aristyawan P Nurdiansyah Implementasi Rangkaian R-2R Ladder DAC dengan Optimisasi Linearitas Menggunakan Algoritma Genetika, Universitas Negeri Surabaya Indonesia 2018

[5] B. Rahmat, T. A. Rachmanto, M. Waluyo, M. I. Afandi, H. Widyantara, dan Harianto, "Designing Intelligent Fishcarelab System (IFS) as Modern Koi Fish Farming System", International Seminar on Application for Technology of Information and Communication, Aug 2016.

[6] Y. Sanjaya, A. Fauzi, D. Edikresnha, M. Munir, dan Khairurrijal, "Air Temperature Regulation in a Chamber for Rotary Forcespinning", International Seminar on Sensor, Instrumentation, Measurement and Metrology (ISSIMM), Aug 2016.

[7] ECG leads: from electrodes to limb lead, chest lead \& 12-lead ECG,https://ecgwaves.com/topic/ekg-ecg-leads-electrodes-systems-limb-chestprecordial/,30 Maret 2021 
[8] Arduino, https://www.arduino.cc/en, 29 Maret 2021

[9] Getting Started with the Arduino Pro Mini, https://www.arduino.cc/ en/Guide/Arduino ProMini, 29 Maret 2021

[10] CD74HC595 8Bit Shift Registers with 3-State Output Registers, Texas Instruments, 2004

[11] LCD Module 16x2Character 16x2, WH1602L datasheet, Winstar

[12] HD44780U (LCD-II) Dot Matrix Liquid Crystal Display Controller/Driver, Hitachi Ltd., 1998. 